\title{
THE AFFECTS OF ENVIRONMENT POLLUTION IN THE PERSPECTIVE OF AIR POLLUTION, WATER AND LAND/SOIL WASTE POLLUTION
}

\section{*Devender Kumar}

\begin{abstract}
Environment pollution is a wide-arriving at issue and it is probably going to impact the wellbeing of human populaces is extraordinary. This paper gives the understanding perspective about the impacts of environment pollution in the perspective of air pollution, water and land/soil waste pollution on human by maladies and issues, animals and trees/plants. Study finds that these sorts of pollutions are not just truly influencing the human by infections and issues yet additionally the animals and trees/plants. Still time left in the hands of worldwide establishments, governments and neighborhood bodies to utilize the development assets to adjust the environment for living and starts the inhaled erudite people to live amicable with environment. As successful answer to tainting is to a great extent dependent on human examination of the issue from each age gathering and pollution control program develops as an across the country fixed cost-sharing exertion depending upon intentional interest..
\end{abstract}

Keywords: Environment Pollution; Air Pollution; Water Pollution; Soil Pollution; Land Pollution, Decay etc.

\section{Introduction}

Environmental pollution is one of the most difficult issues confronting humanity and other life frames on our planet today. Environmental pollution is characterized as "the sullying of the physical and organic parts of the earth/air framework to such a degree, that ordinary environmental procedures are antagonistically influenced." Pollutants can be normally happening substances or energies, yet they are viewed as contaminants when in abundance of regular levels. Any utilization of characteristic assets at a rate higher than nature's ability to reestablish itself can bring about pollution of air, water, and land.

The importance of environmental elements to the wellbeing and prosperity of human populaces' is progressively obvious. Environment pollution is an overall issue and its capability to impact the wellbeing of human populaces is extraordinary. Pollution arrives at its most genuine extents in the thickly settled urban-modern focuses of the more created nations. In poor nations of the world over $80 \%$ contaminated water have been utilized for water system with just seventy to eighty percent nourishment and living security in modern urban and semi urban territories.. Industry, grouped in urban and semi-urban zones encompassed by thickly populated, low-salary regions, keeps on contaminating the environment without risk of punishment. Throughout the most recent three decades there has been expanding worldwide worry over the general wellbeing impacts credited to environmental pollution. Environmental pollution is gone head to head with the unsustainable anthropogenic exercises, bringing about significant general medical issues. (Khan, 2004). McGeehin et al, (2004) revealed that U.S. populace from irresistible ailments to illnesses, for example, malignancy, birth deformities, and asthma, a significant number of which might be related with environmental exposures.

By and large, environmental pollution happens when the environment can't process and kill hurtful side-effects of human exercises at the appointed time with no basic or useful harm to its framework. Despite the fact that pollution has been known to exist since life started, it has seen a development of really worldwide extents since the beginning of the

modern insurgency during the nineteenth century. Environmental pollution is an issue in the created 
nations as well as in creating nations. Factors, for example, populace development, mechanical progression, and urbanization perpetually place more prominent requests on the planet and stretch the utilization of common assets to the most extreme. Pollution is something that we face on an ordinary premise; most likely, this is something we may even be safe to in our quick paced lives. There are three significant sorts of environmental pollution: air, water, and land pollution. Air and commotion pollution are expanding at a disturbing rate today. Air pollution happens with the expansion of hurtful synthetics into the Earth's climate. The principle contaminations that reason air pollution are carbon monoxide, Chlorofluorocarbons, nitrogen oxides, and sulfur dioxide. Water pollution is caused when wastes are discharged into the water, which sullies it. Soil can even be tainted because of different local and modern exercises. Clamor pollution is additionally a current environmental issue that causes hurt in different manners.

\section{Water Pollution}

Water poisons incorporate defilement because of household wastes, bug sprays and herbicides, nourishment preparing waste, contaminations from domesticated animals tasks, unstable natural mixes (VOCs), overwhelming metals, concoction waste, and others. Waterborne maladies brought about by contaminated drinking water incorporate typhoid, amebiasis, giardiasis, ascariasis, hookworm, and so forth. Waterborne sicknesses brought about by dirtied sea shore water are rashes, ear throb, pink eye, respiratory contaminations, hepatitis, encephalitis, gastroenteritis, the runs, spewing, stomach hurts, and so forth. At the point when water is debased with synthetic substances, for example, pesticides, hydrocarbons, determined natural poisons, or substantial, it could prompt malignancy, including prostate disease and nonHodgkin lymphoma, hormonal issues that can disturb regenerative and formative procedures, harm to the sensory system, liver and kidney harm, and harm to the DNA. In particular, mercury in water can cause strange conduct, more slow development and advancement, decreased propagation, and demise.

\section{Air Pollution}

The absolute most significant air contaminations are sulfur dioxide, nitrogen dioxide, carbon monoxide, ozone, VOCs, and airborne particles with radioactive toxins. Burning of non-renewable energy sources creates amazingly elevated levels of air pollution and is a principle zone currently in center for control. The general effects or impacts of air pollution on people incorporate decreased lung working, aggravation of eyes, nose, mouth, and throat, asthma assaults, respiratory side effects, for example, hacking and wheezing, expanded respiratory illness, for example, bronchitis, diminished vitality levels, migraines, and tipsiness, interruption of endocrine, conceptive, and resistant frameworks neurobehavioral scatters, and cardiovascular issues, and it can here and there even lead to disease and unexpected passing. The effect of corrosive downpour demolishes fish life in lakes and streams. Corrosive downpour can execute trees, decimate the leaves of plants, and can invade soil by making it unacceptable for reasons for nourishment and home. Unreasonable bright radiation originating from the sun through the ozone layer in the upper environment, which is disintegrated by some air poisons, may cause skin malignant growth in untamed life. Ozone in the lower environment may harm lung tissues of animals. Ozone gaps in the upper air can permit inordinate bright radiation from the sun to enter the Earth making harm trees and plants.

\section{Land Pollution}

Soil pollution is because of defilement from modern and household toxins. Some basic soil poisons are hydrocarbons, solvents, and substantial metals. Petroleum products likewise add to soil defilement and water pollution. Regular wellsprings of non-renewable energy source pollution incorporate power-creating plants, oil treatment facilities, petrochemical plants, generation and dispersion of petroleum products, street transport (engine vehicles), and transportation and aircraft businesses. 4 Environmental Management Heavy metal pollutions in soil is as a rule much of the time saw in both created and creating nations. Lead in soil is particularly unsafe for small kids, making formative harm the mind, and significant levels of mercury can expand the danger of kidney harm; cyclodienes can prompt liver harmfulness and cause issues identified with misery of the focal sensory system just as causing cerebral pains, sickness, weariness, eye bothering, and skin rash. The local division is another critical wellspring of pollution creating metropolitan strong waste that may wind up in landfills or incinerators prompting soil defilement and air pollution. Soil sullying may change plant digestion and decrease crop yields. Trees and plants may ingest soil contaminants and leave them behind the natural way of life (Mishra, 2003).

\section{Deforestation}

Woods are significant property of a country since they give crude materials to present day businesses, timber for building purposes, natural surroundings for various sorts of animals and small scale living beings. Great fruitful and supplement rich soils having high substance of natural issue, offer assurance to soils by restricting the soils through 
the system of their underlying foundations and by shielding the soils from direct effect of falling raindrops. They energize and increment invasion of rainwater and in this way permit most extreme revive of groundwater assets, limit surface run-off and consequently lessen the recurrence, force and measurement of floods. They help in expanding the precipitation; they are common sink of carbon dioxide since they use carbon dioxide to set up their nourishment during the procedure of photosynthesis. They give kindling to a great many individuals everywhere throughout the world and nourishment and haven to multitudinous people and animals. Actually, timberlands are 'life line' of a country since success and welfare of the general public legitimately relies upon sound and solid backwoods front of a country concerned. Timberlands are primary segment of the biotic segments of the regular environmental framework and the steadiness of the environment and natural parity to a great extent rely upon the status of the backwoods of the locale concerned (Rosenstock, 2003).

\section{Current Scenario of Air Pollution in India}

India is indeed heading into the most noticeably awful season for air pollution, a season where the nation's famously low quality turns out to be considerably progressively poisonous. Residue, residue, ozone, and sulfur oxides are a developing danger for billions of individuals around the globe. The World Health Organization revealed for this present week that 93 percent of all kids on the planet inhale air with pollution levels that surpass their rules. An incredible nine of every 10 individuals on Earth inhale exceptionally dirtied air, and in excess of 80 percent of urban inhabitants need to bear open air pollution that surpasses wellbeing guidelines, as indicated by the WHO's World Global Ambient Air Quality Database. In any case, even among nations panting for breath, India stands apart for air that is reliably, epically awful. Drawing on estimations and figuring's starting at 2016 from air observing stations in 4,300 urban areas, the WHO revealed in March that India's urban communities endure the most.

At the point when you take a gander at the databases positioning of particulate pollution in urban areas, 11 of the 12 urban communities with the most significant levels are situated in India. Kanpur, India, populace 3 million, beat the rundown with a yearly normal of 319 micrograms for each cubic meter of PM2.5, the most risky molecule ordinarily estimated. In fact, the WHO doesn't regard its information as a positioning yet rather an estimation of where dangers are. Be that as it may, it's obvious from the report that India is perhaps the least secure nation on the planet to inhale, up there with Bangladesh and Georgia.
With regards to looking at PM10 estimations of the world's biggest urban communities, India's capital Delhi comes in with a yearly normal of 292, in front of Cairo (284), Dhaka (147), Mumbai (104), and Beijing (92), the Washington Post noted.

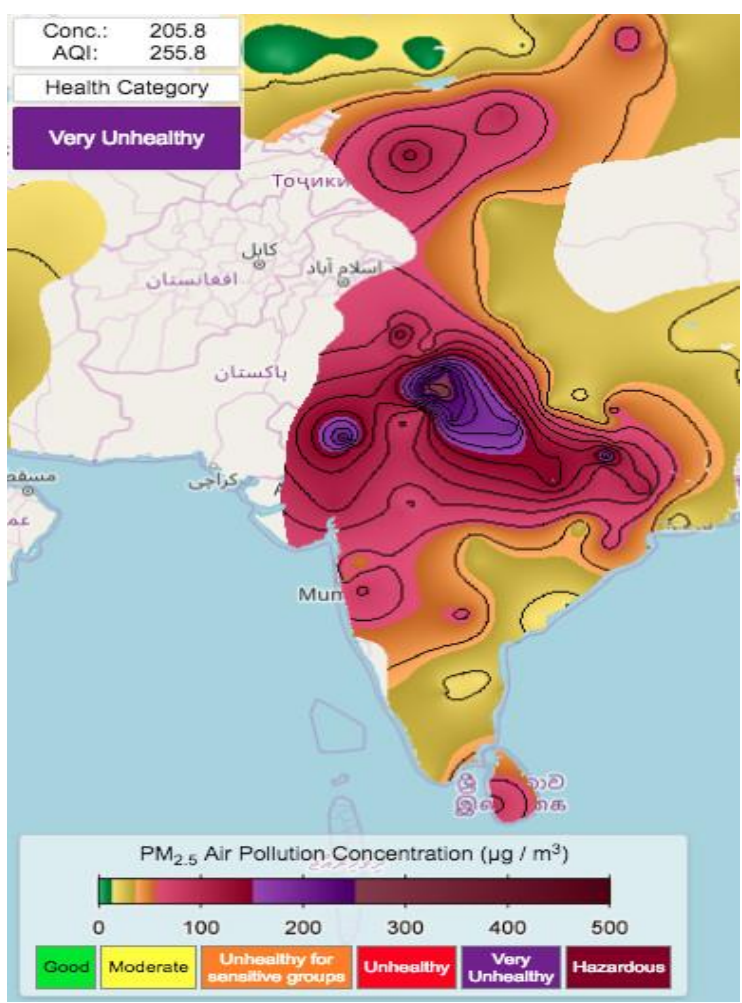

\section{Conclusion}

The reasons for environmental issues are many. The assortment of causes makes it hard to unmistakably portray the causes and results of environmental debasement as far as straightforward coordinated relationship. The circumstances and end results are regularly entwined in complex snare of social, innovative, environmental and political variables. Nonetheless, a portion of the exceptionally normal reasons for environmental debasement which can be obviously called attention to are the populace development, the financial development related with the fortune factor and change of innovation. Populace is a significant asset for advancement, yet it is a significant reason for environmental corruption when it surpasses the edge furthest reaches of the emotionally supportive networks. The superseding effect of unfriendly statistic pressure at last falls on our assets and biological systems. Joined with it the states of neediness and underdevelopment themselves make a circumstance where the individuals are compelled to live in dinginess and further debase their environment. The procedure of improvement itself likewise prompts harm of the environment, if not appropriately oversaw. Related with the fast monetary development, the indulgent wealth expends unmistakably more assets and put 
far more noteworthy weight on common assets. The difference in innovation causes arranged out of date quality causing the age of an ever increasing number of wastes which thusly demonstrate environmentally hurtful. Transient interests of private benefit augmentation, further, hamper the procedure of substitution of out of date innovations by the biologically benevolent advancements.

\section{References}

1. Khan, S. I. (2004), "Dumping of Solid Waste: A Threat to Environment, The Dawn"
2. McGeehin, M. A., Qualters, J. R. \& Niskar, A. S. (2004), "National Environmental Public Health Tracking Program: Bridging the Information Gap" Environmental Health Perspectives; 112(14), 1409-1413

3. Mishra, V. (2003)., "Health Effects of Air Pollution, Background paper for Population Environment Research Network (PERN)" Cyber seminar, December 1-15.

4. Rosenstock, L. (2003), "The Environment as a Cornerstone of Public Health, Environmental Health Perspectives" 111(7), 376-377. 